\title{
Iranian EFL Learners' Interlanguage Request Modifications: Use of External and Internal Supportive Moves
}

\author{
Shahla Amooaliakbari Najafabadi \\ Department of English, Universiti Putra Malaysia, Serdang, Malaysia \\ Email: ash8072@yahoo.com \\ Shamala Paramasivam \\ Department of English, Universiti Putra Malaysia, Serdang, Malaysia \\ Email: shamala@fbmk.upm.edu.my
}

\begin{abstract}
The present study investigated the interlanguage pragmatic knowledge of Iranian English learners at three levels of English language proficiency. The study focused on learners' ability to perform the speech act of request and their performance was compared with American native speakers of English to see to what extent they approximated native speakers in using external and internal modifications. A Discourse Completion Task (DCT) including 12 situations was employed to elicit performance data from 120 participants, 90 Iranian EFL learners and 30 American native speakers of English. The data were categorized using an adapted version of the Cross-Cultural Speech Act Realization Project (CCSARP) classification. The study found that Iranian English learners overused external modifications and underused internal modifications compared to American native speakers. However, they showed pragmatic development toward native speaker norms with increase in language proficiency level. Advanced learners approximated native speakers both in the frequency of use and linguistic form of external modifications with regard to preparator, getting pre-commitment, promise of reward, sweetener, grounder, appreciations, confirmatory, and pre-pre strategies. However they did not approximate native speakers in the frequency of use of external modifications with regard to disarmer and apology strategies, and both in frequency of use and linguistic form of imposition minimizer strategy. In addition, advanced learners approximated native speakers both in the frequency of use and linguistic form of internal modifications with regard to conditional and understater strategies; and in the linguistic form of play down, politeness marker, consultative device, and upgrader strategies. However they did not approximate native speakers both in the frequency of use and linguistic form of downtoner strategy.
\end{abstract}

Index Terms - interlanguage pragmatics, requests, external modifications, internal modifications

\section{INTRODUCTION}

Second language learning involves more than the acquisition of lexical, phonological, and syntactic knowledge of the target language. It also requires learning the pragmatic rules of the language in order to use the language in a native-like manner. Olshtain and Blum-Kulka (1985) mention that a competent second language learner should acquire sociocultural rules appropriately as well as grammatical competence. They pointed out that communication failure may still happen when proficient L2 learners do not have sufficient socio-cultural knowledge.

Since the introduction of the concept of communicative competence, researchers are increasingly recognizing the importance of aspects of pragmatics in second language learning and focusing on interlanguage pragmatic (ILP) studies. Some ILP studies have observed that second language (L2) learners display an L2 pragmatic system that is noticeably different from that of the target language (TL) native speakers, both in production and comprehension (Bardovi- Harlig, 2001; Kasper, 1997). Of the main concern of these studies is examining the production and comprehension of speech acts by second language learners compared to that of native speakers to see to what extent language learners' pragmatic competence deviates or approximates native speakers (Cohen and Olshtain, 1981; Takahashi and Beebe,1987; Trosborg,1995; Hill,1997; Rose, 2000; Churchill, 2001; Pérez i Parent, 2002; Kobayashi and Rinnert, 2003; Hassall, 2003; Holtman, 2005; Pellet, 2005; Taguchi,2006; and Jalilifar, 2009).

Appropriate requests are among one of more important speech acts; they occur very frequently in everyday encounters. The inappropriate use of the request act by non-native learners of language can serve to make them look rude or impolite. In some cases, communication breakdown can occur. It is also widely believed that native speakers consider pragmatic errors to be more serious than phonological or syntactic errors (Koike, 1995; Thomas, 1983; Wolfson, 1989). As Blum-Kulka (1991) points out, requesting style is a good index of a cultural way of speaking. However, in order to appropriately make requests and also perceive the illocutionairy force of an utterance as a request, learners have to acquire sociopragmatic knowledge such as the relative degree of imposition of a speech act in the target 
culture, and pragmatic-linguistic knowledge such as the degree of politeness of utterances in L2 to avoid being considered as rude or impolite by native speakers.

There are several studies that have examined the use of modifications by language learners compared to that of native speakers (House and Kasper, 1987; Blum-Kulka 1989; Trosborg, 1995; Francis, 1997; Hill, 1997; Hassall, 2001; Pérez i Parent, 2002; Barron, 2003; Schauer, 2004; Woodfield, 2006; and Economidou-Kogetsidis 2008 and 2009). Of these Hill (1997), House and Kasper (1987), Francis (1997), and Pérez i Parent (2002) were developmental studies that investigated the pragmatic knowledge of language learners at different levels of language proficiency. The present study aims to make a contribution to the area of ILP by focusing on the use of external and internal modifications by Iranian language learners of English across three language proficiency levels. More specifically, the present study tries to compare the interlanguge pragmatic knowledge of Iranian English learners across three language proficiency levels to that of American native speakers (ANSs) to see to what extent they deviate or approximate native speakers when making requests in English. The aims of the study are to find out:

1. To what extent do Iranian English learners use similar external modifications with ANSs?

2. To what extent do Iranian English learners use similar internal modifications with ANSs?

\section{A. External Modifications}

External modifications are classified in Blum-Kulka et al (1989) CCSARP coding scheme as supportive moves that may be attached either before or after the head act to mitigate the illocutionary force of the request. External modification might serve to either soften or emphasize the force of the whole request. The classification of external modifications is as follows:

_Preparator (e.g. "Hey, you had this management class, right?")

_Grounder (e.g. "I wasn't in class the other day because I was sick.")

_Disarmer (e.g."I know this is short notice")

_Promise of Reward (e.g. "I'll buy you dinner.")

_Imposition Minimizer (e.g. "I will return them in an orderly fashion.")

_Sweetener (e.g. "Today's class was great.")

_Pre-pre strategy (e.g. "Hello sir, how are you today?...")

_Appreciation (e.g."I would appreciate it.")

_Self introduction (e.g. "Hey, I'm in your politics class.")

_Confirmatory strategy (e.g. "I would be grateful if you could help me.")

_Getting a pre-commitment (e. g., "Could you do me a favor? ...”).

_ Apology (e.g. "I'm sorry I can't give you the lesson on Monday.")

\section{B. Internal Modifications}

Internal modifications are classified in Blum-Kulka et al (1989) CCSARP coding scheme as supportive moves in order to mitigate (downgraders) or enhance (upgraders) the illocutionary force of the request. The classification of external modifications is as follows:

Downgraders:

Syntactic Downgraders:

_Play-down (e.g. "I was wondering if I could join your study group.”)

_Conditional (e.g. ". . . if you have time.”)

Lexical/Phrasal Downgraders:

_Politeness marker (e.g. "Can I please have an extension on this paper?")

_Embedding (e.g. "It'd be great if you could put this on the door.")

_Understate (e.g. "If you have a minute, could you help me with this stuff?")

_Appealer (e.g. "I need your computer to finish my assignments, okay?")

_Downtoner (e.g. "Is there any way I could get an extension?")

_Consultative Device (e.g. "Would you mind lending me a hand?")

Upgraders:

_Adverbial intensifier (e.g. "I would be most grateful if you could let me use your article.")

\section{Methodology}

\section{A. Participants}

A total of 120 subjects participated in this study. There were 90 Iranian English learners across three language proficiency levels (advanced, intermediate, and low level language learners) and 30 native speakers of American English. All subjects, aged 20-28, were graduate and undergraduate university students. Iranian participants came from various universities in Isfahan Province and have not had any communication with native speakers of English. American participants came from Tennessee University in America. Ethnic-minority students were excluded from the study in order to avoid influences from other cultures and languages as much as possible. 


\section{B. Instrument}

Data collection in this study was done through an open-ended questionnaire in the form of a discourse completion task (DCT). The DCT involves 12 situations in which each situation was based on the variation of two variables (social power and social distance) (see Appendix A). The social power in this DCT refers to the power of the requester over the requestee and is divided into three levels. The requester with more power than the requestee, the requester with less power than the requestee, and the requester and the requestee with equal power. Social distance refers to the degree of familiarity between the interlocutors and was divided into levels, (a) requester and requestee do not know each other and (b) requester and requestee know each other. The combination of these two variables results in six possible combinations each realized in 2 situations which resulted in 12 situations. The DCT was designed to elicit requests in writing and subjects were given a short description of the situation, which specified the setting, the familiarity, and the social power between the participants. The respondents were asked to put themselves in each situation and to assume that in each situation they would, in fact, say something. They were asked to write down in English what they would say.

\section{Procedures}

Iranian English learners were divided to three groups of low, intermediate, and advanced based on their TOEFL scores done by the institution, then they were asked to complete the DCT to find out their interlanguage pragmatic competence in making requests in English. The DCT was also sent to 30 American native speakers for the base line data The responses collected through DCT form participants were classified in line with the types of external and internal modifications based on CCSARP coding scheme proposed by Blum-Kulka et al., (1989). Then, the data was submitted to SPSS (version 17). Firstly, the total frequency and percentage of external modifications and internal modifications used by participants were calculated. Then chi-square $\left(\mathrm{X}^{2}\right)$ test was applied to test whether differences among the four groups of participants were significant. In addition, a description and comparison of the differences in the linguistic forms for each strategy among the groups was done.

\section{RESULTS AND DISCUSSION}

\section{A. Question 1}

To identify the type and the frequency of external modifications used by Iranian EFL learners and native speakers, the data was analyzed, and the frequency of occurrence and percentage of each type of strategy were calculated as shown in Table 1.

TABLE 1

\begin{tabular}{|c|c|c|c|c|}
\hline \multirow[b]{2}{*}{ Strategy Type } & \multicolumn{3}{|c|}{ Proficiency Level } & \multirow{2}{*}{$\begin{array}{l}\text { Native Group } \\
\text { F }(\%)\end{array}$} \\
\hline & $\begin{array}{l}\text { Low } \\
\text { F }(\%) \\
\end{array}$ & $\begin{array}{l}\text { Intermediate } \\
\mathrm{F}(\%)\end{array}$ & $\begin{array}{l}\text { Advanced } \\
\mathrm{F}(\%)\end{array}$ & \\
\hline Preparator & $7(0.91)$ & $14(2.83)$ & $26(6.6)$ & $30(8.7)$ \\
\hline Getting pre-commitment & $1(0.13)$ & $4(0.81)$ & $12(3.05)$ & $20(5.84)$ \\
\hline Disarmer & $0(0)$ & $0(0)$ & $4(1.01)$ & $13(3.8) \mathrm{f}$ \\
\hline Reward & $0(0)$ & $0(0)$ & $2(0.5)$ & $3(0.8)$ \\
\hline Sweetener & $0(0)$ & $0(0)$ & $2(0.5)$ & $5(1.46)$ \\
\hline Grounder & $360(47.05)$ & $211(42.79)$ & $190(48.34)$ & $174(50.87)$ \\
\hline Imposition minimizaer & $67(8.75)$ & $39(7.91)$ & $24(6.1)$ & $9(2.63)$ \\
\hline Pre-pre strategy & $80(10.45)$ & $60(12.17)$ & $56(14.24)$ & $41(11.98)$ \\
\hline Appreciation & $87(11.37)$ & $56(11.35)$ & $34(8.65)$ & $23(6.72)$ \\
\hline Confirmatory Strategy & $43(5.62)$ & $31(6.28)$ & $17(4.32)$ & $8(2.33)$ \\
\hline Apology & $120(15.68)$ & $78(15.82)$ & $26(6.61)$ & $16(4.67)$ \\
\hline Total & 765 & 493 & 393 & 342 \\
\hline
\end{tabular}

Iranian participants overused total number of external modifications compared to native speakers (NSs). Although they overused external modifications across all proficiency levels, they made developmental progress in the direction of NSs norms by decreasing their use of external modifications. The chi-square test showed that these differences were significant among (low, intermediate, advanced, and NSs) and within groups (low, intermediate and advanced), but was not significant between groups (advanced and NSs). Language learners' overuse of external modifications has been argued by Hassall (2001) as learners desire to claim their linguistic competence, showing that they are able to produce lengthy utterances.

Nonnative speaker overuse of external modifications in making requests and development toward native norms have been supported by several studies conducted within the CCSARP framework, such as Suh (1999), Al-Momani (2009), House and Kasper (1987), Blum-Kulka and Olshtain (1986), Edmondson and House (1991), Faerch and Kasper (1989), Rintell and Mitchell (1989), Trosborg (1995), Hill (1997), and Rose (2000). Results of this study both confirm the overuse of external modifications by language learners and the developmental progress of language learners toward native norms with increase in language proficiency level. 
Iranian learners underused preparator strategy compared to NSs. The chi-square test showed that these differences among NSs and Iranian learners $\left(\mathrm{X}^{2}=17.597, \mathrm{P}=0.0005, \mathrm{P}<0.05\right)$, and across three language proficiency levels $\left(\mathrm{X}^{2}=11.787, \mathrm{P}=0.002, \mathrm{P}<0.05\right)$ were statistically significant, but it was not significant between advanced and NSs. The analysis of data showed that as language proficiency level increased language learners increased their use of preparators and used more similar preparators compared to NSs. Moreover, advanced learners approximated NSs both in the number and linguistic forms of preparators.

Getting pre-commitment strategy was underused by language learners compared to NSs. The chi-square test showed that it was not significant between advanced and NSs. A comparison of the linguistic forms of this strategy showed that low proficient learners used this strategy only once and combined it with politeness marker "please" and modal verb "can". Intermediate learners increased their use of this strategy compared to low proficient learners and made it by combining politeness marker "please" and modal verb "could". Advanced learners increased their use of this strategy compared to low and intermediate learners and used linguistic forms such as "would it be possible" and "I was wondering if", with a higher use of "would it be possible". NSs used more getting pre-commitment strategy compared to advanced learners but they used similar patterns as advanced learners with a greater use of "I was wondering" linguistic form. The analysis showed that with increase in language proficiency level, language learners increased their use of this strategy; and advanced learners approximated native norms both in the number and linguistic form of this strategy.

Iranian participants underused disarmer strategy compared to NSs. It was seen that only advanced learners and NSs used this strategy; however, NSs used significantly more disarmers compared to advanced learners. Advanced learners as well as NSs used linguistic forms such as "I know" and "I understand" for making disarmer in their requests. The data showed that even though advanced learners used few disarmers they are similar to NSs linguistically.

Sweetener strategy was not frequently used by any of the subject groups. Nevertheless, Iranian participants showed developmental progress toward native norms by increasing the use of this strategy as their proficiency increased. NSs used this strategy five times and used structures such as "I know you can help me" and "I know you can understand my problem" in their requests. Advanced learners, the same as NSs, used sweetener strategy infrequently and used similar linguistic forms to NSs such as "I know you can help me". Advanced learners approximated NSs both in the number and linguistic forms of sweetener strategy.

Grounders were the most frequently used form of external modification by all groups. Language learners overused this strategy compared to NSs. The chi-square test showed that these differences among NSs and Iranian learners $\left(X^{2}=93.864, P=0, P<0.05\right)$, and across three language proficiency levels $\left(X^{2}=67.729, P=0, P<0.05\right)$ were statistically significant, but it was not significant between advanced and NSs. The comparison of grounder strategy across groups showed that advanced learners approximated NSs in the number of use of this strategy.

Imposition minimizers were overused by all language learners compared to NSs. The chi-square test showed that these differences among NSs and Iranian learners $\left(\mathrm{X}^{2}=52.856, \mathrm{P}=0, \mathrm{P}<0.05\right)$, across three language proficiency levels $\left(X^{2}=21.985, P=0.00001, P<0.05\right)$, and between advanced and NSs were significant. The analysis showed that all language learners used significantly more and different types of imposition minimizer compared to NSs. NSs used significantly less imposition minimizer strategy compared to other groups and used linguistic forms such as "I assure you", "I would be very careful with it", "I can have it back soon", and "it doesn't take me long". Advanced learners used significantly more imposition minimizers compared to NSs and less than intermediate and low learners, and only used linguistic forms like "I promise", and "it won't take long". Low and intermediate learners used various linguistic forms of imposition minimizer; however, the forms were different from advanced and NSs such as "I only borrow for few days", "I return it soon", I promise give it back soon", and so on. The analysis of data showed that although the use of imposition minimizers decreased toward native norms and advanced learners used significantly less imposition minimizer strategies compared to low and intermediate learners, the difference in the use of this strategy between advanced learners and NSs was significant. In addition, advanced learners did not approximate native norms in the linguistic forms of their strategies.

Pre-pre strategy was overused by language learners compared to NSs. The chi-square test showed that these differences among NSs and Iranian learners $\left(\mathrm{X}^{2}=13.076, \mathrm{P}=0.004, \mathrm{P}<0.05\right)$ were significant; but it was not significant across three language proficiency levels $\left(\mathrm{X}^{2}=5.061, \mathrm{P}=0.07, \mathrm{P}>0.05\right)$. The chi-square test also showed that these differences between native and advanced participants $\left(\mathrm{X}^{2}=2.32, \mathrm{P}=0.1, \mathrm{P}>0.05\right)$ and between native and intermediate participants $\left(\mathrm{X}^{2}=3.574, \mathrm{P}=0.058, \mathrm{P}>0.05\right)$ were not significant. Low proficient learners used considerably more strategies than other groups and used phrases such as "hi", "how are you?" and "how are you doing?" in their requests. Intermediate groups decreased their use of pre-pre strategies and used similar linguistic forms as low proficient learners. Advanced learners used considerably less pre-pre strategies compared to the two other learner groups and almost used similar linguistic forms. Although NSs used less pre-pre strategy compared to the advanced group these differences were not significant and they used almost similar linguistic forms compared to other groups. The analysis of pre-pre strategy showed that as language proficiency level increased, the use of this strategy decreased towards native norms; moreover all language learners used almost same linguistic forms compared to NSs.

Language learners overused appreciation strategy compared to NSs; however, they decreased the use of this strategy toward native norms as language proficiency level increased. The chi-square test showed that these differences among 
NSs and Iranian learners $\left(\mathrm{X}^{2}=47.8, \mathrm{P}=0, \mathrm{P}<0.05\right)$, and across three language proficiency levels $\left(\mathrm{X}^{2}=24.034, \mathrm{P}=0.000006\right.$, $\mathrm{P}<0.05)$ were statistically significant, but it was not significant between native and advanced participants $\left(\mathrm{X}^{2}=2.123\right.$, $\mathrm{P}=0.1, \mathrm{P}>0.05)$. Low and intermediate learners used appreciation strategy frequently in their requests; however, using limited linguistic forms such as "thank you", "thank you very much", and "thanks so much". Advanced learners, on the other hand, used it less frequently with more linguistic forms compared to low and intermediate learners like "thanks", "I would really appreciate", I'll appreciate", I'd be so grateful", and "thank you so much". NSs used fewer number of appreciation strategies compared to all language learners but used more various linguistic forms such as "thanks", "I would really appreciate", "I'd be so grateful", "I'd be ever so grateful", "I would be most grateful", and "I would much appreciate". It was seen that advanced learners approximated NSs both in the number and linguistic forms of appreciation strategy.

Language learners used confirmatory strategy more than NSs did. However, the use of this strategy decreased as language proficiency level increased. The chi-square test showed that these differences among NSs and Iranian learners $\left(\mathrm{X}^{2}=28.798, \mathrm{P}=0.000002, \mathrm{P}<0.05\right)$, and across three language proficiency levels $\left(\mathrm{X}^{2}=11.165, \mathrm{P}=0.0003, \mathrm{P}<0.05\right)$ were statistically significant, but it was not significant between advanced and NSs $\left(\mathrm{X}^{2}=3.24, \mathrm{P}=0.07, \mathrm{P}>0.05\right)$. The analysis of data showed that all language learners used more confirmatory strategy compared to NSs. The overuse of this strategy may reflect Persian learners' lack of confidence in the initial request, hence they desire to repeat or reformulate it. Both low and intermediate learners used significantly more confirmatory strategy compared to advanced learners and NSs, and both groups used repetitions of original requests as their confirmatory strategy. Advanced learners, on the other hand, considerably decreased their use of this strategy toward native norms and used similar linguistic forms to NSs such as "I'd be grateful if you could help me", "I'll really appreciate if you could help me", and "it would be a great help if you could". Data showed that all of the advanced learners and NSs' uses of confirmatory strategy were modified by statements of appreciation for compliance.

Language learners frequently used apology strategy as an external modification, whereas NSs used it less. The results of chi-square test showed that these differences among NSs and Iranian learners $\left(\mathrm{X}^{2}=116.933, \mathrm{P}=0, \mathrm{P}<0.05\right)$, across three language proficiency levels $\left(\mathrm{X}^{2}=59.393, \mathrm{P}=0, \mathrm{P}<0.05\right)$, and between advanced learners and NSs were significant. The results showed that although advanced learners used significantly less apology strategy compared to low and intermediate learners, they used significantly more strategies compared to NSs. The analysis of data indicated that the use of this strategy decreased toward native norms with increase in language proficiency level; however, advanced learners did not approximate NSs in the use of this strategy and used considerably more strategies.

\section{B. Question 2}

To identify the type and the frequency of internal modifications used by Iranian EFL learners and NSs, first of all the data was analyzed, and the frequency of occurrence and percentage of each type of strategies were calculated as shown in Table 2.

TABLE 2

\begin{tabular}{|c|c|c|c|c|c|c|}
\hline & & & Proficiency & Level & & \\
\hline \multirow{9}{*}{ 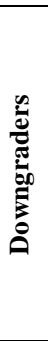 } & \multirow{3}{*}{ 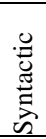 } & Strategy Types & $\begin{array}{l}\text { Low } \\
\text { F }(\%)\end{array}$ & $\begin{array}{l}\text { Intermediate } \\
\mathrm{F}(\%)\end{array}$ & $\begin{array}{l}\text { Advanced } \\
\mathrm{F}(\%)\end{array}$ & $\begin{array}{l}\text { Native Group } \\
F(\%)\end{array}$ \\
\hline & & Play-down & $0(0)$ & $7(3.31)$ & $22(8.97)$ & $53(16.35)$ \\
\hline & & Conditional & $0(0)$ & $42(19.9)$ & $31(12.65)$ & $19(5.86)$ \\
\hline & \multirow{6}{*}{ 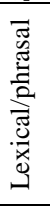 } & Politeness marker & $96(52.74)$ & $75(35.54)$ & $65(26.53)$ & $32(9.87)$ \\
\hline & & Embedding & $0(0)$ & $0(0)$ & $0(0)$ & $5(1.54)$ \\
\hline & & Understater & $56(30.76)$ & $37(17.53)$ & $25(10.2)$ & $21(6.48)$ \\
\hline & & Appealer & $22(12.08)$ & $19(9)$ & $5(2.04)$ & $0(0)$ \\
\hline & & Downtoner & $0(0)$ & $3(1.42)$ & $9(3.67)$ & $40(12.34)$ \\
\hline & & Consultative Device & $0(0)$ & $11(5.21)$ & $56(22.85)$ & $98(30.24)$ \\
\hline \multirow{2}{*}{\multicolumn{2}{|c|}{ Upgrader }} & Adverbial intensifier & $8(4.39)$ & $17(8.05)$ & $32(13.06)$ & $56(17.28)$ \\
\hline & & Total & 182 & 211 & 245 & 324 \\
\hline
\end{tabular}

Iranian participants underused internal modifications across three language proficiency levels compared to NSs. Nevertheless they made developmental progress in the direction of the NSs' norms by increasing their use of internal modifications as their proficiency increased. The chi-square test showed that the difference between advanced and NSs $\left(\mathrm{X}^{2}=10.968, \mathrm{P}=0.0009, \mathrm{P}<0.05\right)$ in the use of internal modifications was significant. Iranian participants made progress in the use of internal modifications as the $X^{2}$ test showed the difference between advanced and low participants $\left(\mathrm{X}^{2}=9.295, \mathrm{P}=0.002, \mathrm{P}<0.05\right)$ in using internal modifications was significant, showing progress toward the native norms

The underuse of internal modifications has been reported by many researchers such as Kasper (1981), Trosborg (1995), Hill (1997), and Al-Momani (2009). These researchers believe that the underuse of internal modifications by learners of English may be ascribed to L1 interference, or perhaps as a result of the lack of linguistic knowledge. The results of his study showed an increase in the number of internal modifications as language proficiency level increased.

Iranian participants underused play-down strategy compared to NSs. The differences among NSs and Iranian learners $\left(X^{2}=79.524, P=0, P<0.05\right)$ and across three language proficiency levels $\left(X^{2}=29.484, P=0, P<0.05\right)$ were significant. NSs 
considered the use of play-down "I was wondering if' as the second most important internal modifier, using it in $19.77 \%$ of their requests. This modifier was used by NSs with a speaker perspective "I was wondering if I could" and with a hearer perspective "I was wondering if you could". The data showed that NSs used this modifier with a hearer perspective in $42 \%$ of the time and with a speaker perspective in $17 \%$ of the time. This modifier was not used by low proficient learners and was used only 7 times by intermediate learners who used it only with the speaker perspective. Advanced learners used this modifier 22 times and used the hearer perspective more than the speaker perspective. Intermediate learners used the expression "I was wondering if" combined with the modal verb "can", while advanced and NSs combined it with the modal verbs "would" or "could" but never with "can". The analysis of this strategy showed that advanced learners used significantly less play-down strategies compared to NSs; but there was an increase toward native norms as language proficiency level increased. In addition, the analysis of strategy forms showed that advanced learners approximated NSs' norms in the use of linguistic forms and the linguistic perspective.

Conditional downgrader was used by NSs in $25 \%$ of their syntactic downgraders. Intermediate participants used conditionals $85 \%$ while advanced participants used them $59 \%$ of their syntactic downgraders. The chi-square test showed that these differences among NSs and Iranian learners $\left(\mathrm{X}^{2}=42.174, \mathrm{P}=0, \mathrm{P}<0.05\right)$, and across three language proficiency levels $\left(\mathrm{X}^{2}=38.986, \mathrm{P}=0, \mathrm{P}<0.05\right)$ were significant, but it was not significant between advanced and NSs $\left(\mathrm{X}^{2}=2.88, \mathrm{P}=0.08, \mathrm{P}>0.05\right)$. A linguistic form comparison of conditional strategy showed that low proficient learners never used this strategy. There is the possibility that perhaps conditionals are taught at higher levels of language learning and that low proficient learners lack grammar knowledge in using this strategy. Intermediate learners overused this strategy compared to advanced learners and NSs. The reduction in this strategy by advanced learners showed that they found it inappropriate to use it frequently. Although intermediate learners used conditional clauses frequently, these clauses were combined with modals such as "can" and "will", while advanced and NSs combined conditional clauses with "would" and "could". The analysis of conditionals showed that advanced learners approximated native norms by decreasing their use of conditionals and by using similar linguistic forms to NSs.

The politeness marker was overused across three language proficiency levels. The chi-square test showed that the differences among the NSs and Iranian learners $\left(\mathrm{X}^{2}=31.851, \mathrm{P}=0, \mathrm{P}<0.05\right)$, across three language proficiency levels $\left(\mathrm{X}^{2}=6.364, \mathrm{P}=0.04, \mathrm{P}<0.05\right)$, and between advanced and NSs were significant. The linguistic comparison of politeness marker "please" across groups showed that low proficient learners used this marker in initial and final positions of their requests. Intermediate learners used this marker in middle and final positions; however, they used it more in final positions, but never used it in the initial position. Advanced learners used this marker both in middle and final positions with more use in middle positions. NSs as well used this marker in middle and final positions with more use in middle positions. Although data showed that advanced learners used significantly more politeness marker compared to that of NSs, the linguistic form analysis of this marker showed significant development by advanced learners in the positioning of the politeness marker.

The understaters were overused by Iranian language learners. The chi-square test showed that differences among NSs and Iranian learners $\left(X^{2}=21.317, P=0.00009, P<0.05\right)$, and across three language proficiency levels $\left(X^{2}=12.424\right.$, $\mathrm{P}=0.002, \mathrm{P}<0.05)$ were statistically significant, but it was not significant between advanced and $\mathrm{NSs}\left(\mathrm{X}^{2}=0.348, \mathrm{P}=0.5\right.$, $\mathrm{P}>0.05)$. A linguistic form comparison of understater across groups showed that while low proficient learners used only "a little", which is probably a translation of Persian language, advanced learners used understaters such as "for a while" and other understaters which were more similar to NSs. This progress by advanced learners indicates that they approximated native norms in the use of the linguistic form. The analysis of understaters showed that as language proficiency level increased language learners decreased their use of understaters toward native norms. Moreover, the results showed that advanced learners approximated NSs both in the number and linguistic form of and understaters.

Downtoner strategy was underused by language learners compared to NSs. The chi-square test showed that these differences among NSs and Iranian learners $\left(X^{2}=78, P=0, P<0.05\right)$, across three language proficiency levels $\left(X^{2}=10.5\right.$, $\mathrm{P}=0.005, \mathrm{P}<0.05)$, and between advanced and NSs $\left(\mathrm{X}^{2}=19.612, \mathrm{P}=0.000009, \mathrm{P}<0.05\right)$ were significant. The comparison of downtoner linguistic form among groups showed that NSs used a variety of downtoners such as "perhaps", "possibly", "by any chance", and "at all possible". The data showed that low proficient learners never used downtoners; and intermediate learners only used "just" which is perhaps a translation from the Persian language. It was shown that although advanced learners used more downtoners compared to low and intermediate learners, they used it significantly less than NSs and only used forms such as "maybe" and "anyway". The analysis of downtoners showed that advanced learners made progress in increasing their use of downtoners; however, it is still far from native norms. The analysis of linguistic forms showed that advanced learners did not make significant progress toward the native norms in the use of downtoners.

Consultative devices were underused by language learners compared to NSs. The chi-square test showed that these differences among NSs and Iranian learners $\left(\mathrm{X}^{2}=146.782, \mathrm{P}=0, \mathrm{P}<0.05\right)$, across three language proficiency levels $\left(\mathrm{X}^{2}=78.836, \mathrm{P}=0.04, \mathrm{P}<0.05\right)$, and between advanced and NSs $\left(\mathrm{X}^{2}=11.455, \mathrm{P}=0.00074, \mathrm{P}<0.05\right)$ were significant. The linguistic form comparison of consultative device showed that low proficient learners never used these modifiers and intermediate learners used only the linguistic form "would you mind". Advanced learners significantly used more consultative devices compared to intermediate learners and used "would you mind" and "do you think?" phrases. They used "would you mind" phrases more frequently; however, they used it less than NSs. The data showed that advanced 
learners used the same linguistic forms as NSs. The data showed advanced learners did not approximate NSs in the number of consultative devices; however, used similar forms compared to NSs.

NSs used adverbial intensifiers significantly more than language learners. The chi-square test showed that these differences among NSs and Iranian learners $\left(\mathrm{X}^{2}=46.752, \mathrm{P}=0, \mathrm{P}<0.05\right)$, and across three language proficiency levels $\left(\mathrm{X}^{2}=15.474, \mathrm{P}=0.0004, \mathrm{P}<0.05\right)$ were significant. A linguistic form comparison of adverbial intensifiers across groups showed that low proficient learners used it occasionally and used limited linguistic forms such as "so" and "very". Intermediate learners significantly increased their use of adverbial intensifier compared to low proficient learners, and used more variant types of adverbial intensifiers like "so", "very", and "very much". Advanced learners both approximated NSs in the number and linguistic forms of adverbial intensifiers such as "most", and "very".

\section{CONCLUSION}

The results of the analysis of external modifications showed that although overall Iranian learners used more external modifications compared to NSs, the total use of external modifications decreased toward native norms as language proficiency level increased. Although there was total decrease in the use of external modifications, the analysis of each strategy type showed that it was not always decreasing. Language learners decreased overused strategies and increased underused strategies in the direction of native norms. The findings show that in this study, the use of preparator, precommitment, disarmer, reward, and sweetener strategies increased and the use of grounder, imposition minimizer, prepre strategy, appreciation, confirmatory, and apology strategies decreased toward native norms as language proficiency level increased. In addition, the data shows that based on the number of strategies, advanced learners approximate NSs in all strategies except disarmer, imposition minimizer, and apology strategies. There were significant differences between advanced learners and NSs in the number of these strategies. Moreover, the analysis of linguistic forms show that advanced learners could use similar strategies compared to NSs in all external modification strategies except imposition minimizer strategy.

Regarding to the use of internal modifications, the results of this study show that language learners underused total number of internal modifications compared to NSs; however, the total number of internal modifications by language learners increased in the direction of native norms as language proficiency level increased. However, there was a significant difference between advanced learners and NSs in the total number of internal modifications. The results showed that as language proficiency level increased, the use of play-downs, consultative devices, downtoners, and adverbial intensifiers increased while the use of conditionals, politeness markers, understater, and appealers decreased in the direction of native norms. However, there were significant differences between advanced and NSs in the use of play-downs, politeness markers, embeddings, appealers, downtoners, consultative devices, and adverbial intensifiers, while advanced learners approximated NSs in the use of conditionals and understaters. Thus, the results of internal modifications show that although language learners showed development toward native norms in all strategies, except embeddings, they did not approximate native norms even at the advanced level, suggesting the lack of knowledge in the use of internal modifications when making requests. The analysis of linguistic forms for each strategy showed that advanced learners approximated NSs in the use of play-down, conditionals, politeness marker, understaters, consultative devices, and adverbial intensifiers. However, they did not approximate NSs in the linguistic form of downtoners and embeddings.

The major deviances found in this study, in the requestive behavior of Iranian learners of English, are as follows:

Underuse in disarmer strategy,

Significant overuse in imposition minimizers even at advanced levels,

Failure to make similar linguistic forms in using imposition minimizers,

Significant overuse of apology strategy even by advanced level learners,

Significant underuse of play-down strategy even at the advanced level,

Significant overuse of politeness marker even at the advanced level,

Significant underuse of downtoner strategy including advanced level learners,

Failure to make similar linguistic forms in using downtoner strategy even at the advanced level, and

Significant underuse of consultative device strategy by the advanced level learners.

This experiment contributes to the field of interlanguage pragmatics by highlighting the sociopragmatic features of Iranian EFL learners in the performance of the requestive speech act. It is hoped that this study will illustrate the significance of interlanguage pragmatic studies among EFL educators and researchers and stimulate their research interest in this fast growing discipline. This type of study not only is useful in supplying L2 teachers and materials developers with NSs baseline data, but also indicates how, and in what situations, Iranian English learners of varying proficiency deviate from NSs' norms. Language teachers could use the requesting behaviour employed by the advanced Iranian learners (as they are the more competent speakers) as part of their English lessons when teaching Iranians because trying to emulate the nuances of a native version of English can sometimes be daunting to learners who may not achieve native-like detail. We believe that although, learners should be offered native models for making requests in English, the goal of teaching pragmatic practices may not necessarily be to encourage language learners to achieve native-like speech proficiency. There is an assumption that NSs norms are an ideal target for non-native speakers; however, privilege constructs of nativeness in English are debatable on the cross-cultural, functional, and pragmatic 
ground (Canagarajah, 1999; Kachru, 2001; Seidlhofer, 2005). It has also been argued that a total convergence with NSs norms may not be desirable from the native and non-native point of view. Non-natives may choose being distinct to assert their identity, and NSs may prefer some degree of divergence as a sign of fully belonging to the target community. Our suggestion is that L2 learners be given input (both native forms and usage as well as those of competent non-native speakers) to help them understand what is appropriate and what is not, what is rude, and what is polite or impolite; and they should be allowed to make their own decisions on how to respond. Learners should be comfortable enough in L2 to decide to be rude, polite or impolite intentionally rather than inadvertently. However, if they produce some strategies excessively, such as the apology strategy by the language learners across the three proficiency levels in this study, the instructor should point out their deviation from the English norms and discuss its possible consequences, but should not instruct learners to correct it, as mentioned by Kasper (1982, p.109) that L2 sociopragmatic use ought to be pointed out and discussed, but errors in this area should not be corrected because it is in part culture-specific, which is a reflection of the students' system of values and beliefs. It should, therefore, be a major goal in English language teaching to teach cultural schemata and to make non-native learners aware of differences between their own cultural schemata and those of NSs. Instructors should remind students that in teaching sociopragmatics the intent is not to impose values and beliefs on learners, but to inform them of differences in sociopragmatic norms between cultures and how these norms are reflected in language.

As sequels to this study, we suggest that future research on Iranian EFL learners' interlanguage pragmatics examine the effect of different social variables particularly social power and social distance on their requesting behaviour. More studies are needed to unveil and explore these issues.

\section{APPENDiX A Discourse COMPLETION TASK (DCT)}

Directions: Please read the following descriptions of situations and write what you would say in each situation.

1. You are taking a course in sociology. In today's class, the professor mentions a new article "Religion \& Culture". You are interested in the topic so you go to the library to read the article. Unfortunately, the library does not have the article, and you decide to borrow it from the professor. This is your third course with this professor and you have a good relationship with him/her. You go to the professor's office and say...

2. You are graduating this semester and planning to apply for the Master's program. You need to submit a recommendation letter with the application, and you want your "Academic Advisor", who you know well, to write it for you. You go to the professor's office and say...

3. Tomorrow is the deadline for one of your final papers. You have many other assignments and cannot finish the paper on time. This is your first course with this professor and you have never spoken with him/her before; however, you decide to talk to the professor about an extension on the paper. You go to the professor's office and say...

4. You have to take a course in (psychology) in order to graduate. The section that suits your time is closed and you have to get the professor's permission to add it. You have never met the professor before but you decide to see him/her about adding the course. You go to the professor's office and say...

5. You have been helping your neighbor, a high school student, with his/her studies for two months now. Your next meeting with him/her is Monday evening. You have an exam on Tuesday and you want to postpone your appointment with your neighbor till Wednesday evening. You say...

6. You are living in a first- floor apartment. You have an exam tomorrow and you are trying to study. You can't focus because your neighbor's kids, in 9th and 10th grades, are playing football outside your window. You have been neighbors for more than a year now. You want to ask them to play somewhere else. You open the window and say...

7. You are a university professor. You have a department meeting and you have to cancel one of today's classes. One of the course students stops by your office to inquire about one of the requirements. This is the student's first course with you and you don't know him that well. You want the student to post an announcement about cancelling today's class at the classroom door. You say...

8. You are a university professor. This is the first day in the semester and you are teaching a course for first year students. You come to today's class carrying many books and papers to share with students. The class finishes and you want a student to help you carry the books to your office. You look at a student standing close to you and say...

9. You have been sharing an apartment with a friend for two years now. While you were working on your assignments, your computer stopped working. You want to use your friend's computer and finish your assignments. You go to your friend and say...

10. You are taking a course in "Management", and you are required to buy an expensive book. You do not think that you will be using the book after this semester. You want to borrow it from your friend who took the same course last semester. You go to your friend and say...

11. You are taking a course in "Politics". Last week, you had a bad cold and missed very important classes. You see one of your classmates in the library. You have never spoken with this classmate before but you know that he/she is an excellent student, and you want to copy his/her notebook. You go to your classmate and say...

12. You are having trouble understanding your (Mathematics) course. You hear that some of the course students have formed a study group to prepare for the midterm exam. You have never spoken with those students before but you decide to talk to them about joining the study group. You approach one of study group students and say... 


\section{REFERENCES}

[1] Alcon, S. E. (2005). Does instruction work for learning pragmatics in the EFL context? System 33.3, 417-435.

[2] Al.Momani, H. S. (2009). Caught between two cultures: The realization of requests by Jordanian EFL learners. Ph.D. dissertation, Indiana: University of Pennsylvania.

[3] Bardovi-Harlig, K. (2001). Evaluating the Empirical Evidence: Grounds for Instruction in Pragmatics? In K. R. Rose \& G. Kasper (eds.), Pragmatics in Language Teaching. New York: Cambridge University Press, 13-32.

[4] Bardovi-Harlig, K. \& M.R Taylor (eds.) (2003). Teaching pragmatics. Washington DC, US Department of State: Office of English Language Programs.

[5] Barron, A. (2003). Acquisition in Interlanguage Pragmatics: How to do things with words in a study abroad context. Amsterdam, Philadelphia: Benjamins.

[6] Blum-Kulka, S. (1991). Interlanguage Pragmatics: The Case of Requests. In R. Phillipson, E. Kellerman, L. Salinker, M. Sharwood Smith \& M. Swain (eds.). Foreign/Second Language Pedagogy Research. Clevedon and Philadelphia: Multilingual Matters, 255-272.

[7] Blum-Kulka, S., J. House \& G. Kasper (eds.) (1989). Cross-cultural pragmatics: Requests and apologies. Norwood, NJ: Ablex.

[8] Blum-Kulka, S. \& E. Olshtain (1986). Too many words: Length of utterance and pragmatic failure. Studies in Second Language Acquisition 8, 165-180.

[9] Churchill, E. (2001). The effect of a study abroad program on request realizations by Japanese learners of English. Kanagawa University Studies in Language 24, 94-103.

[10] Cohen, A. \& E. Olshtain (1981). Developing a measure of sociolinguistic competence: The case of apology. Language Learning 31, 13-134.

[11] Economidou-Kogetsidis, M. (2008). Internal and external mitigation in interlanguage request production: The case of Greek learners of English. Journal of Politeness Research Language, Behaviour, Culture 4.1, 111-137.

[12] Economidou-Kogetsidis, M. (2009). Interlanguage request modification: The use of lexical/phrasal downgraders and mitigating supportive moves. Multilingua 28, 79-112.

[13] Edmondson, W. \& J. House (1991). Do learners talk too much? The waffle phenomenon in interlanguage pragmatics. In R. Phillipson, E. Kellerman, L. Selinker, S. Smith \& M. Swain (eds.). Foreign/second language pedagogy research. Clevedon, U.K.: Multilingual Matters, 273-287.

[14] Faerch, C. \& G. Kasper (1989). Internal and external modification in interlanguage request realization. In S. Blum-Kulka, J. House \& G. Kasper (eds.). Cross-cultural pragmatics. Norwood, NJ: Ablex, 221-47.

[15] Francis, C. (1997). Talk to me! The development of request strategies in nonnative speakers of English. Working Papers in Educational Linguistics 13.2, 23-40.

[16] Hassall, T. (2001). Modifying requests in a second language. International Review of Applied Linguistics in Language Teaching 39, 259-283.

[17] Hassall, T. (2003). Requests by Australian learners of Indonesian. Journal of Pragmatics 35, 1903-1928.

[18] Hill, T. (1997). The development of pragmatic competence in an EFL context. Ph.D. dissertation, Temple University: Japan.

[19] Holtman, K. C. (2005). The Acquisition of the Speech Act of Complimenting by Second Language Learners of French. Ph.D. dissertation, Indiana University.

[20] House, J. \& G. Kasper (1987). Interlanguage pragmatics: Requesting in a foreign language. In W. Lorscher \& R. Schulze (eds.). Perspectives on language in performance. Tubingen, Germany: Gunter Narr, 1250-1288.

[21] Jalilifar, A. (2009). Request strategies: Cross sectional study of Iranian EFL learner and Australian native speakers. English Language Teaching 2, 466-61.

[22] Kachru, B.K. (2001).why the time is right for India to exploit its most valuable export commodity: English. Learning English, Supplement to the Guardian Weekly.

[23] Kasper, G. (1982). Teaching-induced errors in interlanguage discourse. Studies in Second Language Acquisition 4, 99-113.

[24] Kasper, G. (1997). Can Pragmatic Competence be Taught? Paper presented at the TESOL Conference, Orlando, FL.

[25] Kasper, G. \& K. R. Rose (1999). Pragmatics and SLA. Annual Review of Applied Linguistics 19, 81-104.

[26] Kobayashi, H. \& C. Rinnert (2003). Coping with high imposition requests: High vs. low proficiency EFL students in Japan. In A. M. Flor, E. U. Juan \& F. Guerra (eds.). Pragmatic competence and foreign language teaching. Castello de la Plana: Publicacions de la Universitat Jaume I, 161-183.

[27] Koike, A. (1995). Transfer of pragmatic competence and suggestions in Spanish foreign language learning. In S. Gass \& J. Neu (eds.). Speech acts across cultures: Challenges to communications in a second language. Berlin: Mouton de Gruyter, 251-281.

[28] Olshtain, E. \& S. Blum-Kulka (1985). Degree of approximation: nonnative reactions to native speech act behavior. In S. M. Gass \& C. G. Madden (eds.). Input in second language acquisition. Cambridge, MA: Newbury House, 303-325.

[29] Pellet, S. H. (2005). The development of competence in French interlanguage pragmatics: The case of the discourse marker 'donc'. Ph.D. dissertation, University of Texas, Austin.

[30] Pérez i Parent, M. (2002). The production of requests by Catalan learners of English: Situational and language proficiency le vel effects. ATLANTIS. XXIV.2, 147-168.

[31] Rintell, E. \& C. J. Mitchell (1989). Studying requests and apologies: An inquiry into method. In S. Blum-Kulka, J. House \& G. Kasper (eds.). Cross-cultural Pragmatics Norwood, N.J.: Ablex, 248-272.

[32] Rose, K. R. (2000). An exploratory cross-sectional study of interlanguage pragmatic development. Studies in Second Language Acquisition 22, 27-67.

[33] Schauer, Gila (2004). May you speak louder maybe? Interlanguage pragmatic development in requests. In S. Foster-Cohen, M.S. Smith, A. Sorace \& M. Ota (eds.). EUROSLA Yearbook (Vol.4). Amsterdam: John Benjamins, 253-273.

[34] Suh, J. (1999). Pragmatic perceptions of politeness in requests by Korean learners of English as a second language. International Review of Applied Linguistics in Language Teaching 37, 195-213.

[35] Taguchi, N. (2006). An analysis of appropriateness in a speech act of request in L2 English. Pragmatics 16.4, 513-533. 
[36] Takahashi, T. and Beebe, L.M. (1987). The development of pragmatic competence by Japanese learners of English. Japan Association for Language Teaching 8, 131-155.

[37] Thomas, J. (1983). Cross-cultural pragmatic failure. Applied Linguistics. 4: 91-112.

[38] Trosborg, A. (1995). Interlanguage pragmatics: Requests, complaints, and apologies. Berlin, Germany: Mouton de Gruyter.

[39] Wolfson, N. (1989). Perspectives: Sociolinguistics and TESOL. Rowley, MA: Newbury House.

[40] Woodfield, H. (2006). Requests in English: ESL learners' responses to written discourse completion tests. Paper presented at the 31st International LAUD Symposium. Intercultural Pragmatics, Linguistics, Social and Cognitive Approaches. Landau/Pfalz, Germany.

Shahla Amooaliakbari Najafabadi is a Ph.D. English Language candidate at the Department of English, Faculty of Modern Languages and Communication, Universiti Putra Malaysia (UPM). She worked for 3 years as English teacher in Darkoub Industrial Forging Co, Iran. She has a 2-year research assistant experience at Universiti Putra Malaysia. She has presented papers in conferences such as Second International Conference on Iranian Linguistics, Hamburg, Germany and Malaysia International Conference on Language, Literature and Culture. She also participated in a Workshop in Phonetics, Uppsala University, Sweden. Her research interests lie in pragmatic development, interlanguage pragmatics, and second language acquisition.

Shamala Paramasivam is an Associate Professor at the Department of English, Faculty of Modern Languages and Communication, Universiti Putra Malaysia (UPM). She has taught English language at the university since 1991. She has published in several international journals including Journal of Asian Pacific Communication, Journal of Intercultural Communication, Journal of Universal Language, Asian EFL Journal, and Journal of Language and Linguistics. She has presented papers in conferences such as Asia Pacific Airline Training Symposium, International Aviation English Forum, International Conference on Discourse, Communication and Enterprise, International Conference on Politeness Research, and European Conference for Academic Disciplines. She has a specialization in language use in intercultural communication, English for Specific Purposes (ESP), and Teaching English as a Second language (TESL). Her research interests lie in discourse, communication, and culture in educational and professional settings, particularly in business and workplace communication. 